\title{
Cultura Cultura
}

Revista de Historia Teorid das ldeaias - Revista de História e Teoria das Ideias

Vol. 23 | 2006

Ideia(s) de Tempo(s)

\section{Os ciclos de tempo no México Antigo}

Time cycles in Ancient Mexico

\section{Miguel Conde}

\section{OpenEdition \\ Journals}

Edição electrónica

URL: http://journals.openedition.org/cultura/1460

DOI: 10.4000/cultura.1460

ISSN: 2183-2021

\section{Editora}

Centro de História da Cultura

\section{Edição impressa}

Data de publição: 1 Janeiro 2006

Paginação: 221-231

ISSN: 0870-4546

\section{Refêrencia eletrónica}

Miguel Conde, "Os ciclos de tempo no México Antigo », Cultura [Online], Vol. 23 | 2006, posto online no dia 08 abril 2014, consultado a 20 abril 2019. URL : http://journals.openedition.org/cultura/1460

DOI : 10.4000/cultura.1460

Este documento foi criado de forma automática no dia 20 Abril 2019.

(c) CHAM - Centro de Humanidades / Centre for the Humanities 


\title{
Os ciclos de tempo no México Antigo
}

\author{
Time cycles in Ancient Mexico
}

Miguel Conde

\section{Introdução}

1 Os calendários têm como base a astronomia e os cálculos matemáticos geralmente a ela associados. Este fundo científico não lhes retira nenhuma versatilidade: podem assumir aspectos por vezes muito diversos, de acordo com as diferentes necessidades. No entanto, todos tentam, de uma forma ou de outra, relacionar o que passámos com o que antecipamos para o futuro.

2 Para criar um destes calendários formais necessitamos de estabelecer diferentes pontos de referência cíclicos: o sol, a lua, um planeta, uma planta que nasce ou um animal que ressurge, vindo da sua migração ou despertando da hibernação.

3 Na Mesoamérica, ${ }^{1}$ os ciclos de tempo reflectem-se na vida agrícola, religiosa, social e até no urbanismo (através do eixo de orientação dos edifícios ou mesmo do das cidades). São disso exemplo os 365 nichos da pirâmide de El Tajin, um por cada dia, que procuram corporalizar a passagem etérea do tempo (fig.1.). A observação da natureza orienta, deste modo, as actividades práticas no tempo e no espaço; e uma maior complexidade social conduz a uma maior sofisticação na observação e desenvolvimento dos calendários, que se articulam com as estruturas cosmogónicas da comunidade. 
Fig. I . Pirâmide de Nichos de El Tajin.

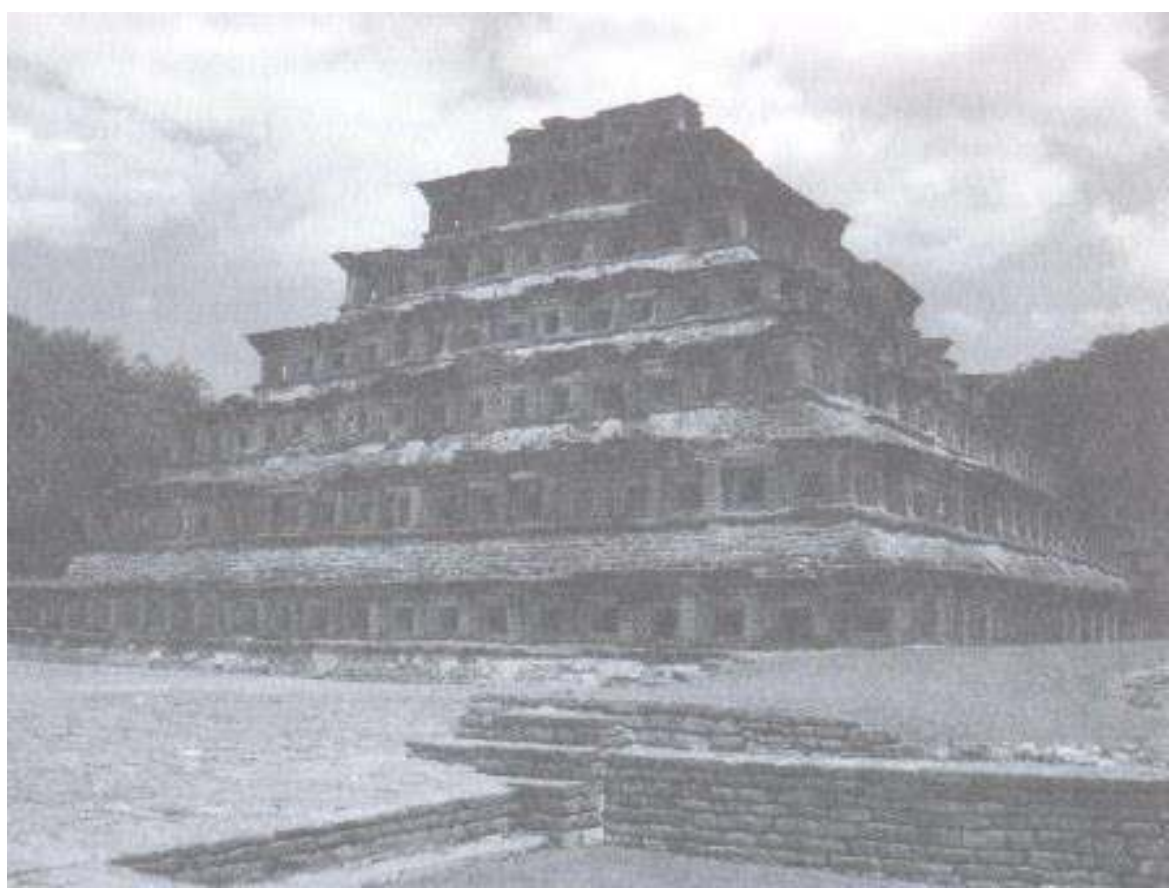

Fig. 2. Distribuição espacial dos calendários mesoamericanos.

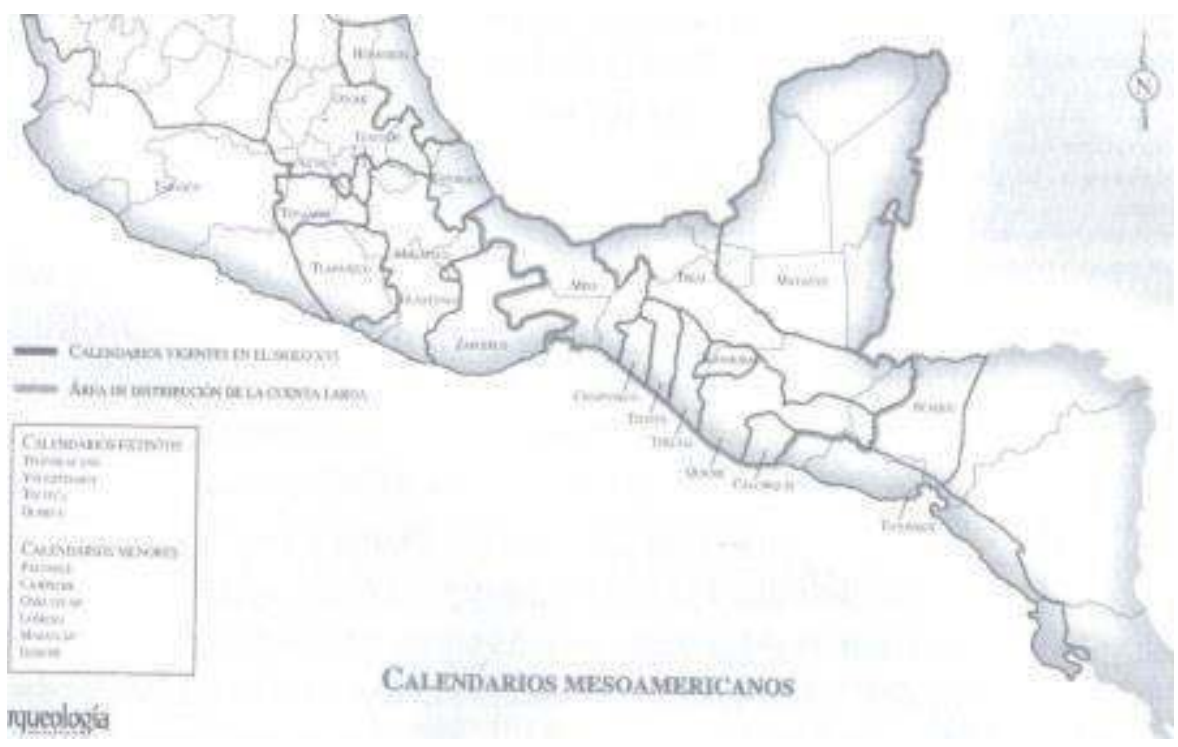

EDMONSON, Munro S, «Los calendarios de la conquista», Arqueologia Mexicana vol. VII $-\mathrm{N}^{\circ} 41$, 2000 , p. 43

Embora haja diversos calendários na Mesoamérica, graças a uma diversidade cultural e a especificidades locais às quais a orografia não é alheia (fig. 2.), podemos identificar ciclos de tempo pan-mesoamericanos. O calendário de 260 dias, que se começou a desenhar ao longo do segundo milénio antes de Cristo, faz mesmo parte de um conjunto de traços que define a mesoamericanidade (vd. nota anterior) e é o mais antigo calendário registado em pedra; registo que se encontra na zona zapoteca e que data de meados do primeiro milénio a.C. ${ }^{2}$ A estrutura deste calendário é igual de região para região mas há detalhes 
que variam, como os nomes dos dias ou os dos anos. Mesmo dentro da Tripla Aliança, Império ao qual podemos chamar Azteca, não há uma padronização desses detalhes. Aliás, nas cidades que constituíam a Tripla Aliança (Tenochtitlan, Texcoco e Tlacopan), o ano nem sequer se iniciava no mesmo dia.

Em nome da clareza vamos usar como base nesta análise os calendários dos Mexicas de Tenochtitlan, complementados pelos dos Maias das Terras Baixas. A estrutura é a mesma e as pequenas diferenças que ocorrem têm mais que ver com a expressão do que com o conteúdo.

\section{As formas calendáricas}

6 Na Mesoamérica existem dois calendários nucleares. 0 de 365 dias, que está relacionado com o ano trópico e que tem um carácter fortemente ritual e mágico, chama-se em náhuatl xiuhpohualli (conta dos anos) e em maia haab. Este calendário articula-se com o ciclo de 260 dias, o tonalpohualli (conta dos dias) ou tzolkín. A combinação destes ciclos formava a maior unidade cronológica mesoamericana "conta curta», a de 52 anos. É o chamado «século mesoamericano». Apenas os Maias clássicos desenvolveram a «conta longa», uma cronologia absoluta a partir de uma data zero.

\section{Xiuhpohualli}

7 Este calendário está organizado em 18 «meses» de vinte dias (vintenas) ao qual se juntam 5 dias extra cada ano, os nemontemi (dias nefastos) ou uayeb, totalizando assim 365 dias, havendo a possibilidade de ano bissexto. ${ }^{3} \mathrm{O}$ papel deste calendário trópico, que marcava o passar dos anos, ao acompanhar os astros e os ciclos da natureza, era o de determinar os inúmeros rituais que nas sociedades do México antigo ritmavam o quotidiano. ${ }^{4}$ Cada uma destas vintenas era caracterizada por um festival que homenageava um deus em particular. $\mathrm{O}$ nome da vintena, à qual podemos chamar mês, era também o do festival realizado nesse período. Por exemplo, o festival Panquetzaliztli, alçamento de bandeiras (em que o deus festejado era Huitzilopochtli, deus guerreiro e patrono dos Mexicas), tinha lugar na vintena Panquetzaliztli.

8 Ainda que as celebrações principais ocorressem no último dia do mês, havia outras actividades e ritos preparatórios, mais ou menos longos, de acordo com a festa em questão, que podiam começar 20, 40 ou até 80 dias antes da celebração principal e, muitas vezes, até terminar para lá desta. Isto significa que muitos rituais se sobrepunham, num entrelaçar cerimonial ao longo de todo o ano. As grandes celebrações tinham lugar no ponto nevrálgico da cidade, ou seja, no caso de Tenochtitlan na Praça Maior. As cerimónias tanto podiam ser de manhã como de noite, à luz de centenas de archotes. Os atavios dos intervenientes eram exuberantes e tudo estava envolto num ambiente teatral, causando um enorme impacto nos protagonistas e na assistência. Estes momentos eram, talvez, a faceta mais visível de uma ideologia de estado que fundia todas as vertentes da sociedade.

9 As cerimónias eram preparadas por sacerdotes especializados, que eram também os principais celebrantes; ainda que nas de carácter militar alguns nobres fossem os intervenientes, assumindo as responsabilidades inerentes à sua condição. Os rituais guerreiros, tais como a referida Panquetzaliztli, centravam-se no culto ao sol, à águia e, por 
conseguinte, o peso que a política assumia no seu desenrolar era por demais evidente. As celebrações da gente comum estavam geralmente relacionadas com o culto à fertilidade (aos deuses da chuva e do milho - o cereal sobre o qual assentava a vida no México Antigo). As datas fundamentais do calendário agrícola são: o início do ano (Fevereiro); a sementeira (Abril); o apogeu das chuvas e crescimento do milho (Agosto) e a colheita (Outubro-Novembro). Assim, as principais celebrações dedicadas aos deuses do milho eram as de Atlcahualo, na estação seca, em que crianças eram sacrificadas nos montes da região (como meios de contratação entre deuses e homens); ${ }^{5}$ a de Huey Tozoztli, em que se festejava a sementeira; e, finalmente, a de Tepeihuitl, já no período da colheita, em que se celebravam os mortos. Estas festas continuam a ser realizadas pelos indígenas, mesmo que já muito cristianizadas. Aliás, as celebrações cristãs do início de Novembro juntaramse ao Tepeihuitl e deram origem ao festival dos mortos tão típico do México de hoje, onde as abundantes ofertas de comida simbolizam o encerramento do ciclo agrícola.

\section{Tonalpohualli}

10 A existência do calendário de 260 dias encontra-se registada desde os otomis, ao norte do México, até aos Nicaragos, na Nicarágua, e esteve em uso oficial até ao ano 1580 d.C., ou seja, por cerca de 2200 anos. De carácter eminentemente ritual e astrológico, a sua utilização ultrapassou em muito o período do encontro com o mundo ocidental. Ainda hoje, em bastantes comunidades rurais indígenas, este calendário é utilizado quotidianamente. Uma das utilidades práticas deste calendário era a de referenciar a passagem dos dias. Para referência ao tempo quotidiano, ao dia do tonalpohualli juntava-se o ano, de que é exemplo a seguinte forma: dia 5-ocelotl (do tonalpohualli e não do Xiuhpohualli) do ano 12-acatl. ${ }^{6}$

11 A origem deste ciclo é incerta, havendo quem o relacione com o período da gestação humana (ainda que em média esta seja um pouco mais longa) ou com uma conjunção dos ciclos da Lua, do Sol e de Vénus. ${ }^{7}$ Porém, o mais provável é que a sua duração esteja relacionada somente com o ciclo solar. Na latitude de $15^{\circ} \mathrm{N}$, que atravessa a zona maia meridional, nomeadamente Izapa e Copan (provável região de origem deste calendário), o tempo que separa as duas passagens anuais do sol pelo zénite é de 105 e 260 dias.

A «conta dos dias», como se chama este calendário, é constituída por 20 signos de carácter divino que se cruzam com os números até 13. Por exemplo, se substituirmos os signos pelas letras de A a T teremos a seguinte sequência: A-1 B-2 C-3 (...) M-13 N-1 (...) T-8 A-1 B-2, etc. Cada um destes dias tem um valor específico, atribuído pelo número e pelo signo que fazem de cada dia uma entidade singular, fundamental para prever o futuro e para interpretar o passado ocorrido numa data definida. o destino de cada um dos homens estava determinado pelos deuses criadores desde sempre, mesmo antes do começo do mundo, e esse destino encontra-se revelado no dia de nascimento, no dia do seu tonalli. ${ }^{8}$

13 A importância deste calendário pode ser atestada pela existência de tonalpouhqui's (sacerdote que lê o tonalamatl - livro dos dias, destinos ou espíritos) aos quais as pessoas pedem conselhos acerca da sua vida ou aos quais recorrem os pais de um recém-nascido. Dirigem-se a ele para saber o futuro da criança; eventualmente podem mesmo alterar o dia «oficial» do nascimento para que o seu futuro seja mais venturoso (fig. 3.). No Códice Florentino encontramos alguns prognósticos do destino, retirados seguramente de um tonalamatl, tais como: 
«Daquele que nasce a 1-Morte diz-se que vai ser rico e próspero, seja nobre ou gente do povo (...) 1- Jaguar, aqueles que então nasciam, fossem nobres ou gente do povo, segundo se dizia, morreriam em guerra, seriam feitos prisioneiros». ${ }^{9}$ Dos que nasciam a 9-crocodilo «dizia-se que não era bom, não era conveniente, que estava cheio de pó e lixo; andrajoso, roupa velha, a total miséria trazia como destino, e com nada se poderia remediar, nada poderia melhorar o seu dia de nascimento». ${ }^{10}$

Fig. 3 . Codex Borbonicus - Tercena de Quetzalcoatl

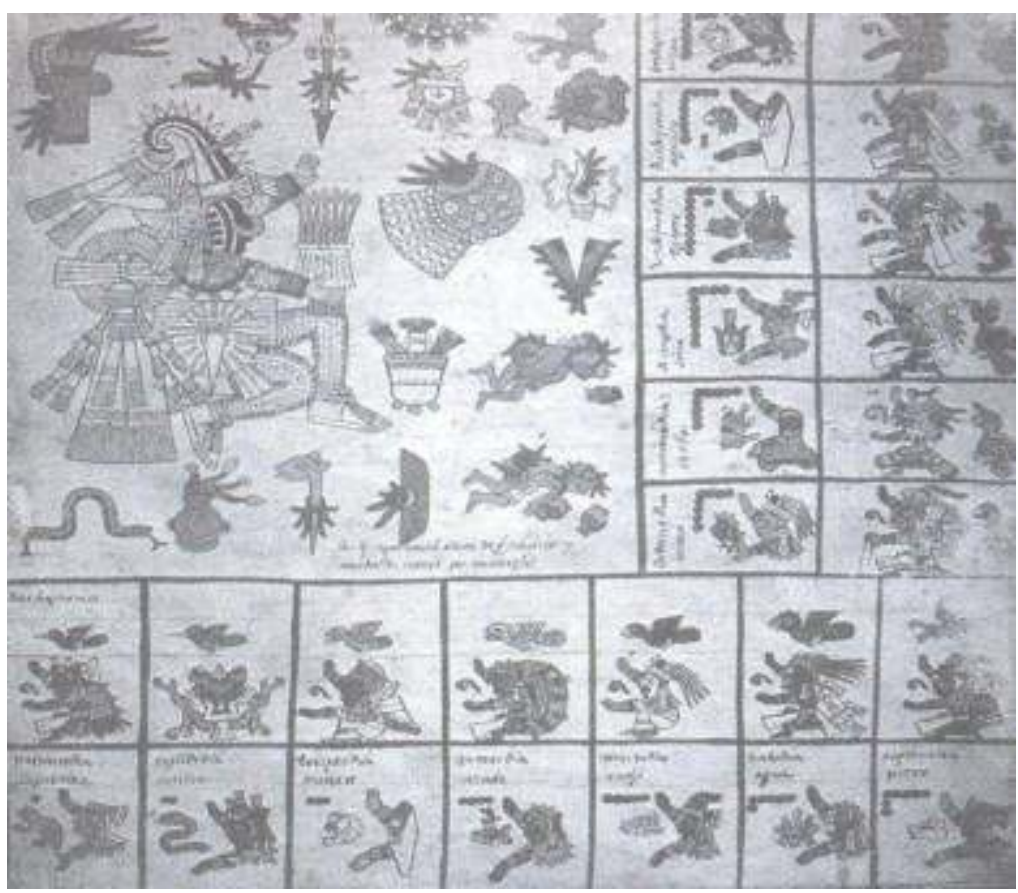

Codex Borbonicus, J. de Durand-Forest e K. A. Nowotny (ed.), Graz, Akademische Druck und Verlagsanstalt, 1974.

Entre os Zapotecos, os Mixtecos e os Mexicas era costume baptizar as crianças, que recebiam nomes de acordo com a sua data de nascimento (2-movimento, 4- flor, 9-jaguar, etc). Porém, outros aspectos importantes são também averiguados: verificar se os noivos são compatíveis (por exemplo, nos Mixtecos os membros de um casal não podiam ter o mesmo nome ou número do dia de nascimento e o ideal era que o número do homem fosse maior que o da mulher), se é sensato partir de viagem a dada altura ou ainda inquirir acerca do tratamento a fazer para curar determinada enfermidade. Recorre-se a uma leitura especializada do tonalpohualli pelo tonalpouhqui, que é médico, sacerdote e psicólogo.

Este calendário, a conta dos dias, podia ser dividido por vários números, tendo todos os resultados significados diversos. A divisão por 5 dava 52, os anos do «século mesoamericano", e que correspondia às 5 regiões do universo (os 4 pontos cardeais mais o centro). A divisão por 13 resultava em 20, o número de deuses associados a este calendário, e a inversa, por 20 , um valor (13, a tercena) que é o que mais se assemelha à nossa semana. 


\section{Os Anos}

E como se referiam aos anos? Embora à primeira vista não pareça, estes sucediam-se e eram nomeados de uma forma sequencial. O nome do ano era atribuído de acordo com o 1 ' dia do ano (do tonalpohualli). E os nomes anos podiam ser 4, acompanhados de números até 13. Se o primeiro dia do primeiro ano tivesse sido ce-tochtli (1-coelho), na sucessão do tonalpohualli, 365 dias depois chegaríamos ao ome-acatl (2-cana), mais 365 dias ao ye-tecpatl (3-pedernal), depois ao nahui-calli (4-casa) e ao $5^{\circ}$ ano ao chicome-tochtli (5-coelho). 0 52 ano nesta sucessão seria o matlactli omey-calli (13-casa). Ao final de 18980 dias estava concluído o «século mesoamericano» e a conta voltava ao 1-coelho.

\section{0 século mesoamericano}

17 A combinação dos ciclos xiuhpohualli e o tonalpohualli, a roda calendárica, leva ao chamado «século mesoamericano» (fig.4).

Fig. 4. Roda calendárica

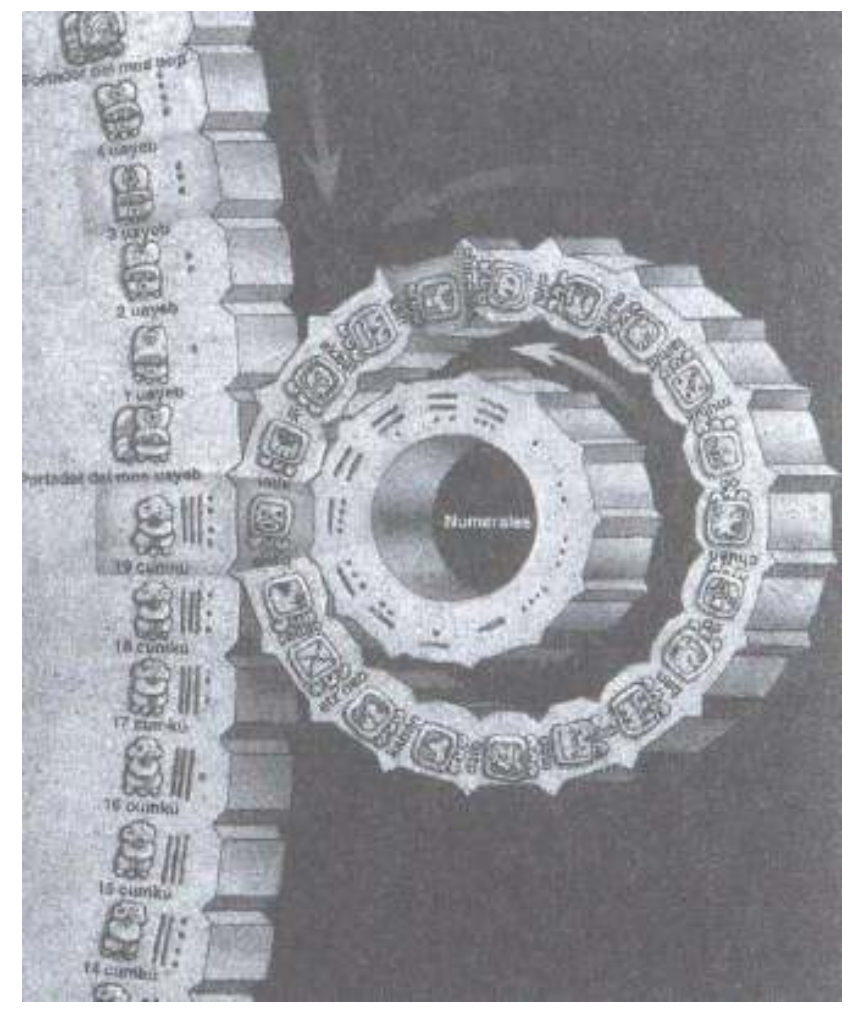

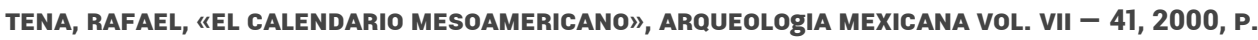
9.

Os nomes dos dias do calendário de 365 dias são diferentes dos do de 260, pelo que em cada ano os dias de cada mês são diferentes. Só ao fim de 52 anos é que dado dia de um calendário se volta a encontrar com outro do segundo calendário. Quando isso se passa, e se inicia o 1-coelho, concluí-se um século e dá-se a «ligação de anos».11

Os Mexicas acreditavam que o mundo tinha tido 4 Eras (ou «sóis») anteriores à actual. Este $5^{\circ}$ sol, criado em Teotihuacan, deveria, deverá, acabar com um grande terramoto, um 
grande movimento (ollin). Esta catástrofe ocorrerá numa das ligações de anos, pelo que o aproximar de um momento potencialmente tão perigoso causava preocupação e motivava uma aturada preparação, que se iniciava com um ano de antecedência. Nos últimos momentos do século partiam-se os objectos domésticos, apagavam-se todos os fogos e as pessoas fechavam-se em casa ou aproximavam-se do local onde se iria acender o Fogo Novo, a cerimónia que marcava este momento. Com o cair da noite a ansiedade subia. No momento exacto da «ligação dos anos», ateava-se um fogo a umas canas colocadas no peito de um guerreiro entretanto sacrificado, guerreiro que teria que, ele próprio, ter 52 anos. Este era o momento chave, o acender do fogo significava que a existência tal como era conhecida se iria prolongar pelo menos por mais 52 anos. Acendido o fogo, este era transportado, com alívio, para os diversos templos da região onde depois cada um ia buscar o seu fogo doméstico. Fechava-se um ciclo, e logo outro se iniciava.

\section{Conta Longa}

Falámos até agora dos registos de tempo cíclicos. No entanto, na zona maia, desenvolveuse também uma contagem linear do tempo, com uma função eminentemente política. $\mathrm{Na}$ verdade, os Maias desenvolveram o que se chamou a «conta longa». Esta era uma forma de registo que partia de um ponto zero, o dia 13 de Agosto de 3114 a.C. e acumulava os dias linearmente.

Controlando este registo os governantes demonstravam dominar milhares de anos, conhecer fenómenos prévios à criação, prognosticar grandes acontecimentos e escolher correctamente as datas indicadas para cada celebração. Desenvolveram, com base neste conhecimento, a ideia de uma continuidade histórica desde o par criador original até eles próprios, reforçando a sua essência divina. A sua linhagem assentava no conhecimento da sucessão e dos momentos em que as transições tinham tido lugar.

Para registar estas datas era necessário ter definido um registo numérico eficiente. Tal como o nosso se baseia em múltiplos de 10 e o mesopotâmico em múltiplos de 60, o maia baseia-se em múltiplos de 20. Assim, cada conjunto de 20 dias (chamados kines) formava um mês ou uinal. Como se procurava aproximar o ciclo ao ano trópico a próxima unidade era multiplicada não por 20 mas sim por $18(20 \times 18=360)$. No entanto, esta operação é uma excepção. A este ano de 360 dias chamava-se tun, que constava de 360 kines, distribuídos por 18 uinales ou vintenas. Vinte tunes formavam um katun (7200 dias) e 20 katunes um baktun (ou seja 144000 dias). Cada Era consistia por 13 baktunes, cerca de 5125 anos trópicos. A sequência de 13 baktunes em que actualmente vivemos termina em 2011 (possivelmente de 12 para 13 de Agosto), e este facto tem dado origem a muita literatura acerca da previsão maia sobre o fim do mundo.

\section{Como se apresentava a Conta Longa}

Os Maias usavam um sistema posicional na apresentação dos números, tal como nós. A diferença é que o faziam na vertical e não na horizontal e usando múltiplos de 20 e não 10, i.e., seria 1, 20, 400, 8000, 160 000. Este sistema posicional, que implicou o uso do conceito de zero, permitia anotar as unidades de tempo acumuláveis de forma linear, embora quando o fizessem utilizassem a adaptação referida de 18 uinales (vintenas) e não 20, para o aproximarem do calendário trópico. Para tudo o resto utilizavam o sistema vigesimal 
«perfeito». A sua apresentação era feita usando um sistema de pontos e barras, em que os pontos valiam um e as barras cinco. uma vida própria que afectavam quotidianamente todas as sociedades mesoamericanas. Para os investigadores actuais, o Tonalpohualli é mesmo considerado um dos marcadores da «mesoamericanidade» de uma comunidade. Não porque seja um elemento acessório mas precisamente porque revela a forma como cada grupo humano estrutura o seu mundo e o seu lugar nele. despicienda. As divergências calendáricas entre as diversas entidades políticas, e até entre as cidades da Tripla Aliança (Tenochtitlan, Tlacopan e Texcoco), podem levar-nos a questionar o grau de hegemonia de algo a que nos acostumámos chamar Império Azteca. Contudo, não podemos ignorar que Tenochtitlan vigiava de perto as actividades dos tonalpohualli. Estes eram formados em escolas estatais onde aprendiam as técnicas necessárias ao seu mester mas também a importância do seu papel na manutenção de uma estrutura social rígida.

Os calendários, em termos gerais, reflectiam-se na vida de todos os membros da sociedade. Originados pela leitura dos ritmos naturais acabavam, por osmose, por institucionalizar os ritmos urbanos. Por seu lado, as celebrações nas pequenas comunidades, onde primeiro se tinha sentido necessidade de um calendário, estavam 
longe da extrema ritualização urbana mas satisfaziam uma vontade de se articular ritualmente com o cosmos que emergira milhares de anos antes da fundação da primeira cidade mesoamericana. Ao longo dessa associação cronológica, realizada pelo espírito humano, o tempo seguia, e segue, indiferente à tentativa de fixação humana dos elementos que o transcendem.

\section{BIBLIOGRAPHY}

BRODA, Johanna, «Calendarios, cosmovisión y observación de la naturaleza», Temas Mesoamericanos (ed.), Mexico, INAH-CONACULTA, 1996, pp. 427-469.

CASO, Alfonso, Los Calendarios Prehispánicos , México, UNAM - IIH, 1967.

CASTILLO FARRERAS, Victor, «El Bisiesto Náhuatl», Estudios de Cultura Nahuatl IX, 1971, pp. 75-104.

Codex Borbonicus, FOREST, J. de Durand e NOWOTNY, K. A. (eds.), Graz, Akademische Druck und Verlagsanstalt, 1974.

Códice Telleriano-Remensis, QUIÑONES, Eloise K. (ed.), Austin, University of Texas Press, 1995.

EDMONSON, Munro S., The Book of the Year. Middle American Calendrical Systems, Salt Lake City, University of Utah Press, 1988.

GRAULICH, Michel, «Acerca del "problema de ajustes del año calendárico mesoamericano al ano trópico"», Estudios de Cultura Náhuatl 33, 2002, pp. 44-56.

HINZ, Eike, «Aspectos sociales del calendario de 260 días en Mesoamerica», Estudios de Cultura Náhuatl 14,1980, pp.203-224.

MARCUS, Joyce, «Los calendarios prehispánicos», Arqueologia Mexicana vol. VII - N 41,2000, pp. 12-19.

SIARKIEWICZ, Elzbieta e SIARKIEWICZ, Marek, «Algunos sistemas calendáricos de los pueblos del altiplano central de México y el problema de correlación con los calendarios cristianos», REAA XV, pp.121-129.

SAHAGÚN, Bernardino de, Historia General de las Cosas de Nueva España, de LOPEZ AUSTIN, Alfredo y GARCIA QUINTANA, Josefina (intr., paleografia, glossário e notas), Mexico, CONACULTA, III Vols., 2000.

SAHAGÚN, Bernardino de, Códice Florentino. Manuscrito 218-20 de la Colección Palatina de la Biblioteca Medicea Laurenziana, ed. Facs. 3 Vols., México, Secretaria de Gobernación, Archivo General de la Nación, 1979.

TENA, Rafael, «El calendario mesoamericano», Arqueología Mexicana vol. VII - N² 41, 2000, pp. $4-11$. 


\section{NOTES}

1. Conceito desenvolvido pelo investigador alemão Paul Kirchoff, como ferramenta de trabalho metodológico, para definir uma área geográfica e cultural que tem como limite norte o rio Panúco, no centro-norte do México, e que a sul chega até ao ocidente da Nicarágua. Esta área é definida pela existência de certos traços culturais idiossincráticos, sendo os principais: o uso do calendário de 260 dias, alimentação baseada no complexo milho, feijão, cabaça e chile, existência de sacrifícios humanos, conhecimento da escrita, prática do jogo da bola e veneração a Quetzalcoatl.

2. Marcus, Joyce, «Los calendarios prehispánicos», Arqueología Mexicana vol. VII - N 41, 2000, p.18.

3. Castillo Farreras, Victor, «El Bisiesto Náhuatl», Estudios de Cultura Nahuatl IX, 1971, pp. 75-104; TENA, Rafael, «El calendario mesoamericano», Arqueología Mexicana vol. VII - № 41, 2000, pp. 10.

4. Broda, Johanna, «Calendarios, cosmovisión y observación de Ia naturaleza», Temas Mesoamericanos (ed.), Mexico, INAH-CONACULTA, 1996, pp. 427-469.

5. As crianças sacrificadas tornar-se-iam tlaloques, auxiliares do deus Tlaloc.

6. Como dizemos 1 de Fevereiro de 2007, por exemplo.

7. Tena, Rafael, «El calendario mesoamericano», Arqueología Mexicana vol. VII - N 41, 2000, p. 5.

8. Conceito que significa «dia» mas também algo que podemos traduzir por «espírito» ou ainda «destino».

9. Sahagún, Bernardino de, Códice Florentino. Manuscrito 218-20 de la Colección Palatina de la Biblioteca Medicea Laurenziana, ed. Facs. 3 Vols., México, Secretaria de Gobernación, Archivo General de la Nación, 1979 Vol. 1. Livro 4, cap. 9 folha 23 fr e vr.

10. Ibidem, Vol. 1. Livro 4, cap. 9 folha 5 fr.

11. Caso, Alfonso, Los Calendarios Prehispánicos, México, UNAM - IIH, 1966.

\section{ABSTRACTS}

A Mesoamérica, área cultural onde surgiu uma das poucas civilizações prístinas, tem como um dos elementos mais idiossincráticos a forma particular como lê o tempo. A face mais visível dessa realidade é a existência de um calendário de 260 dias e o modo como este se articula com os demais calendários. Esse processo contribui para conformar a sociedade enquanto tal e articulála com a visão que esta tem de si própria e do papel que desempenha num cosmos que a transcende. Neste texto pretendemos dar a conhecer alguns dos factos mais característicos dos ciclos de tempo mesoamericanos, mostrar o seu funcionamento e tentar motivar o interesse por um conhecimento mais profundo de uma estrutura mental colectiva singular, como a que encontramos no México Antigo.

One of the most idiosyncratic elements of pre-Columbian cultures in Central America, a geographical area that was the cradle for some of mankind's most pristine civilisations, is the unique way in which they interpret time. The most visible face of this phenomenon is the existence of a calendar with 260 days and the way in which this articulates with other kinds of calendars. This process influenced local society, the view it had of itself and how it was 
integrated into a cosmos that transcended its existence. In this text I will expound upon some of the more characteristic elements of ancient Central American notions of time cycles, demonstrate how these concepts work and try to motivate the interest about a unique and remarkable collective mental structure, as was the case in Ancient Mexico.

INDEX

Keywords: Mesoamerica, Ancient Mexico, Mayas, Aztecs, calendars, time

Palavras-chave: México Antigo, Maias, Aztecas, calendários, tempo

\section{AUTHOR}

\section{MIGUEL CONDE}

Mestrando em Estudos Mesoamericanos Universidad Nacional Autonoma de Mexico.

Licenciado em História pela Faculdade de Ciências Sociais e Humanas da Universidade Nova de Lisboa. Pós-Graduação em Egiptologia pela mesma Faculdade. Pós-Graduação em Estudos Orientais pela Universidade Católica Portuguesa. Mestrando em Estudos Mesoamericanos na Universidad Nacional Autonoma de Mexico. 